\title{
A Proposed Framework for Knowledge Transfer in ERP Implementation Projects
}

\section{Prof. Mohamed M. El Hadi

\author{
Dept. of Computer and \\ Information Systems
}

\section{Hossam El-Sobky}

\author{
Ph.D. Candida in Computer \\ and Information Systems
}

\section{Abstract}

There has been a growing increase in using Enterprise Resource Planning (ERP) systems as a business information system platform for enterprises to assists in automating and integrating its cross-functions such as inventory control, procurement, distribution, finance, and project management, etc. The implementation of such systems is a complex process, and the failure rate remains very high. According to analyst firm Gartner, approximately 75 percent of all ERP projects fail. So, implementing such systems need careful planning and guarding against factors for failure. In order to resolve this costly failure trap and maintain a success path in ERP implementation, many studies identified a set of critical success factors (CSFs) for ERP implementation and for a long time, the knowledge transfer has been recognized as one of the key success factors of the implementation projects. Although researchers and practitioners have pointed out that ignorance of knowledge transfer is the reason for high ERP implementation failure rate, an extra effort must be spent on studying the factors that need to be considered when transferring the knowledge during the ERP implementation. This paper focuses on the activities of knowledge transfer within ERP systems during its implementation. Theories regarding ERP implementations, change management are combined to build a framework for knowledge transfer when implementing ERP systems. The framework is based on the extensive literature search on the ERP implementation projects plus the knowledge and experience of the authors in the subject. The purpose of proposed framework is to find activities of successful ERP implementation from the knowledge transfer perspective. This paper sets out to report on the first stage of broad study to assess the Effectiveness of implementing an enterprise resource planning system (ERP) from a knowledge transfer perspective.

Key-Words:

Enterprise Resource Planning (ERP), critical success factors (CSFs), knowledge Transfer, Implementation Projects.

1 Introduction

Many companies are turning to Enterprise Resource Planning (ERP) systems in order to accomplish corporate goals and enhance organizational performance through end-to-end connectivity. The ERP system is 
large, complex, and its implementation process requires extensive, lengthy and costly effort, typically measured in millions of dollars, Pan et al. (2001). Moreover, it was reported that three quarters of the ERP projects are judged to be unsuccessful by the ERP implementing companies, Griffith and Zammuto (1999). Therefore, how to implement ERP successfully have been the focal interests of many researchers and practitioners. Literature had extensively discussed the key issues, challenges and current status of ERP selection, implementation and use. Knowledge Transfer (KT) has been identified as one of the key success factors for ERP implementation. Because of the high failure rate of ERP systems and the Importance of successful Knowledge Transfer for ERP success, various ERP related studies have researched critical success factors of ERP implementation. But very few Information Systems researchers have analyzed ERP implementation from a knowledge transfer perspective. The purpose of this study is to examine the impact of Knowledge transfer for facilitating the process of ERP Implementation and identify the required activities for integrating $\mathrm{KT}$ in ERP practices to get a successful ERP implementation.

\section{Background}

Through this study, we present a proposed framework for the knowledge transfer activities associated to the ERP implementation projects. To be able to get a deeper understanding of the subject we will discusses the main concepts, necessary definitions, and different fields that will build a proposed framework for knowledge transfer in ERP implementation projects. Then it will be combined to build a framework in the next section.

\subsection{Enterprise Resource Planning (ERP)}

An enterprise resource planning (ERP) system is a system that completely or partly supports the core administrative processes across the company, Shutub (1999). It is also defined as "customizable integrated application software that supports the core business processes and the main administrative areas of enterprise in different industries", Rosemann (1999). The ERP systems are normally standard packages with a built in support for processes like finance, manufacturing, sales, distribution and human resources. Davenport (1998) defines an ERP system as a packaged software product that can be bought off-the-shelf' by an organization in order to integrate and share its information and related business processes within and across functional areas". This definition focus on the integration and sharing business processes information between various functional divisions within organizations like finance, sales and distribution, marketing, inventory, procurement, human resources and payroll. Another important point of view is related to best practices embedded in ERP systems which are supposedly established ways of doing business. Umble et al. (2003) emphasizes that "Buying an ERP package means much more than purchasing software, it means buying into the software vendor's view of best practices for many of company's processes"

\subsection{ERP Implementation Project}

An ERP implementation is a complex and dynamic process whose success is by no means ensured. Researchers have developed different models for ERP implementations. For example, Ross (1999) proposed a five-stage model for ERP: implementation, stabilization, continuous improvement and transformation. Markus \& Tanis (1999) suggested a model named enterprise system experience cycle, which has four phases: charter, project, shakedown and onward and upward. According to ASAP methodology the project consists of five phases: Project preparation, Business blueprint, Re- 
alization, Final preparation, Go-live and support (Ehie and Madsen, 2005). Implementing an ERP system is generally an extensive challenge, with a typical ERP implementation taking between one and five years (Poston \& Grabski, 2001; Robey \& Ross, 2002). Studies have shown that it is an endeavor that fails almost as often as it succeeds, but it is critical to the business that the implementation does succeed. Failures have been relatively high (Carlo, n.d.). Zhang et al. (2003) report that about $90 \%$ of ERP implementations are late or over budget while ERP systems success rate is only about 33\%. Different ERP implementation phases are associated with specific ERP implementation problems (Markus et al., 2000).

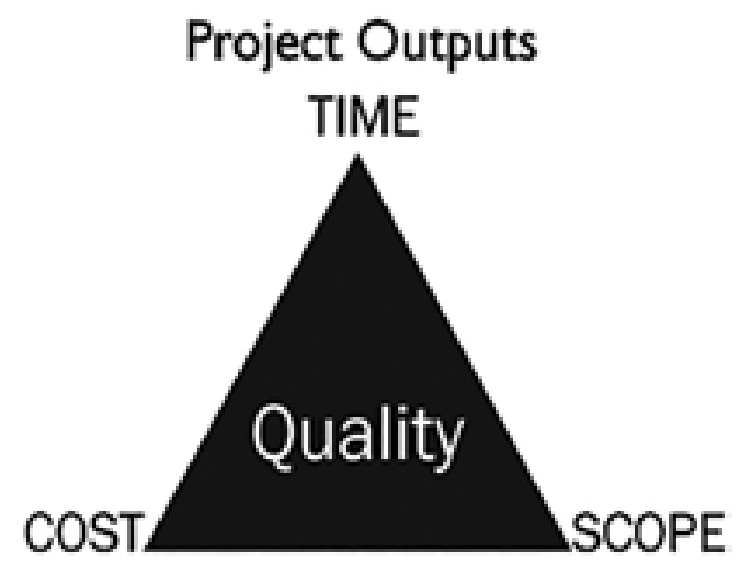

Fig. 1: Project Triple constraints Source: PMI

The Project Management Triangle represented in Fig. 1 is called "Project Triple Constraint or the Iron Triangle", is a model of the constraints of project management. It is a graphic aid where the three attributes show on the corners of the triangle to show opposition. It is useful to help with intentionally choosing project biases, or analyzing the goals of a project. Erik Bethke (2003). Each constraint forms the vertices, with quality as the central theme.

- Projects must be delivered within cost.

- Projects must be delivered on time.
- Projects must meet the agreed scope - no more, no less.

- Projects must also meet customer quality requirements.

Table 1 represents that according to Panorama's independent ERP research over the past five years, from ERP implementation projects, approximately 58-percent exceeded their planned budgets, and 65-percent experienced schedule overruns. Post implementation, 53-percent of organizations achieved less than 50-percent of the measurable benefits they anticipated from new ERP software.

Table 1: ERP over the past five years

\begin{tabular}{|c|c|c|c|c|c|}
\hline YEAR & $\cos 7$ & $\begin{array}{l}\text { Sof COST } \\
\text { OVERRUNS }\end{array}$ & OURATION & $\begin{array}{c}\text { S OF } \\
\text { OURATIOK } \\
\text { OUERAUNS }\end{array}$ & \begin{tabular}{|} 
s \\
RECEIVING \\
SOSOR \\
LESS \\
BENEFITS
\end{tabular} \\
\hline 214 & SHSWM & SWO & 14.3 nortes & $75 \%$ & $41 \%$ \\
\hline 2013 & $\$ 2804$ & $5 \%$ & 16.3 morths & $72 \%$ & $66 \%$ \\
\hline 2012 & $\$ 7.11 \mathrm{M}$ & $5 \%$ & 17.8 mortss & $61 \%$ & $60 \%$ \\
\hline 2011 & \$125Vy & $56 \%$ & 16 noxhs & $54 \%$ & $48 \%$ \\
\hline 2010 & $\$ 5524$ & $75 \%$ & 14,3 morths & 618 & $48 \%$ \\
\hline
\end{tabular}

Source: Panorama 2015 ERP Report

\subsection{ERP Critical Success Factors (CSF)}

The phrase critical success factors are used widely in the business by consultants and IT people to describe the key components of a successful implementation of an information system (King \& Burges 2006). These critical success factors are normally only a list of factors but provide little further guidance to those implementing the systems. In ERP implementations a large number of areas of expertise must be managed. These areas can be categorized into technical and organizational areas (including human). Examples of CSF for ERP implementation are: Top Management Support, Change Management, Project Management, Business Process Re-engineering, Training, ERP Team Compo- 
sition, and Post-implementation Evaluation.

\subsection{ERP Knowledge Transfer Knowledge trans-} fer is the process of sharing knowledge or facilitating the learning of knowledge between one person and another. (Kumar and Ganesh, 2009) define the knowledge transfer as: 'a process of exchange of explicit or tacit knowledge between two agents, during which one agent purposefully receives and uses the knowledge provided by another. 'Agent' can be referred as to an individual, a team, an organizational unit, the organization itself or a cluster of organizations.' The knowledge must both be learned and be useable in a relevant context; if both conditions do not exist, the knowledge has not been transferred. Knowledge types: organization culture, business framework, ERP package and project were the knowledge types identified by Alavi and Leidner (2001). In our proposed framework the knowledge will be transferred during the ERP implementation during the five phases of ASAP methodology (Ehie and Madsen, 2005):

Project preparation: In this phase, first the scope of the project is described and the project objectives are defined. After that, the organization standards for the project are formulated and needed technical requirements are explained. Proper planning and organizational readiness play a central role in this step. Besides, the focus areas which should be regarded are defined and planned (SANKAR et al., 2006). An output of this phase is a document named Project Charter which contains project mission, scope, schedule, structure, communication procedures, document layouts and general technical architecture. Another output of this phase is the initial training for key user based on the applications' standard functionality. The knowledge product of this phase is the initial training.

Business blueprint: This phase documents the busi- ness processes in the company that implement an ERP system. In a Business Blueprint for Projects, a project structure to be created in which relevant business scenarios, business processes and process steps are organized in a hierarchical structure. The Business Blueprint is a detailed description of business processes and system requirements. The output of this phase is a document which results in the preparation of the Business blueprint, containing the design of the future system. The knowledge product of this phase is the Business Blueprint documentation.

Realization: In this phase, the business process requirements determined in the blueprint phase are implemented. The configuration is completed through setting up parameters and designating the main data. Besides, this phase includes testing and releasing of the system (SANKAR et al., 2006). The main cornerstones of this system can be defined as simulation, validation, and testing. The main product of which is the configured and tested system. The knowledge products of this phase are the system documentation and user manuals.

Final preparation: This phase aims to finalize organizational requirements to use the production system and to finish all the preparation activities previously carried out. In this phase, all open points have to be checked and resolved in order to ensure that the production system is used without any problem. Apart from system testing, system management and users training also play a central role in this phase (SANKAR et al., 2006). This phase results in the system ready to run and trained users as the main knowledge product.

Go-live and support: Starting this phase means that the main project management activities are finished and all needed arrangements are made in the production system. Although some activities such as 
user training and system management are also carried out in this phase, these are realized in the production environment, no more in development or quality assurance environments as in previous processes. In this phase the lessons learned are identified and documented which describe the good things and also bad things to take into consideration in further projects. The knowledge product of this phase is the lessons learned documentation.

\section{Proposed Framework Overview}

In this section, we will overview the components and the architecture of the proposed framework. Our proposed framework consists of three main components:

- Knowledge transfer people

- Knowledge transfer methods

- Knowledge transfer procedures

Fig.2 shows the main elements of the proposed framework for knowledge transfer in ERP implementation projects

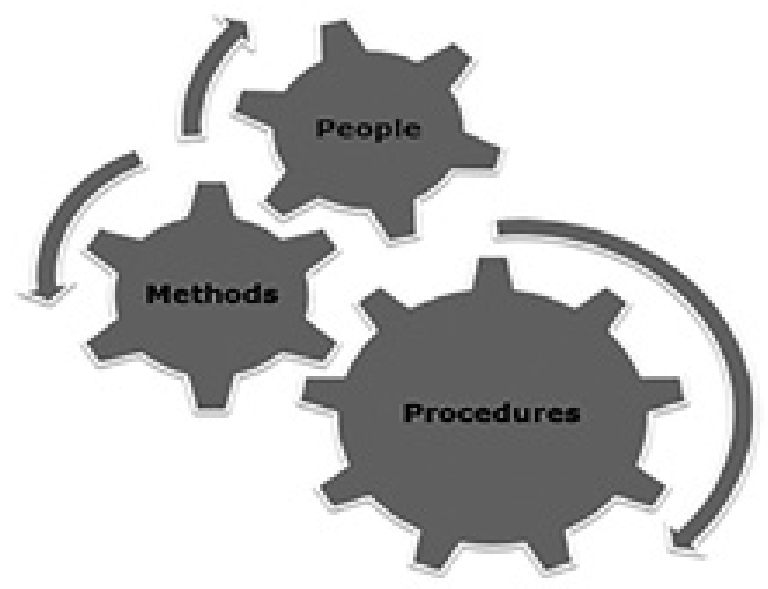

Fig.2: Main elements of the KT framework

\subsection{Knowledge Transfer People}

The first element of our proposed framework is the knowledge transfer teams whom can help garner knowledge transfer process support during the ERP implementation to facilitate their adoption and implemen- tation in projects' everyday practice. Figure 3 shows the main players of the knowledge transfer team in our proposed framework for knowledge transfer in ERP implementation projects:

- ERP Consultants: ERP consultants provide technical and business expertise, reduce the learning burden of clients, configure appropriate ERP systems, and train users to fully exploit the technology. Chan and Rosemann (2001). Chang et al. (2013)

- MIS Coordinators: Management information system coordinators can understand both application and business languages are responsible for: the dayto-day management of the commitments to the project; work as MIS Key users for the total implementation of the project and work in close coordination other key users for the specified modules; participate in the Business Requirements Definition stage and map the business data; coordinating and performing the Application Testing; delivering the end-user training.

- Key Users: They are persons work in different parts of the organizations and are specialists both in the business processes in their area and in how the ERP system works in that area of the business. The main responsibilities of a key user include: participate in the business requirements definition stage; supporting colleagues when they have questions about how they should use the ERP system; be the contact between the implementation project team and the business; be involved in the implementation of the ERP system, to discuss process set up; take certain decisions that might affect the whole business process; map the business data; Review all documents that are provided by consultant; approve the deliverables; attend and contribute in the training offered by the project; transfer the application skills to the end-user (operational user); understand the life cycle of the project, and look for 
practical solutions when functionality is discussed with the subject matter experts.

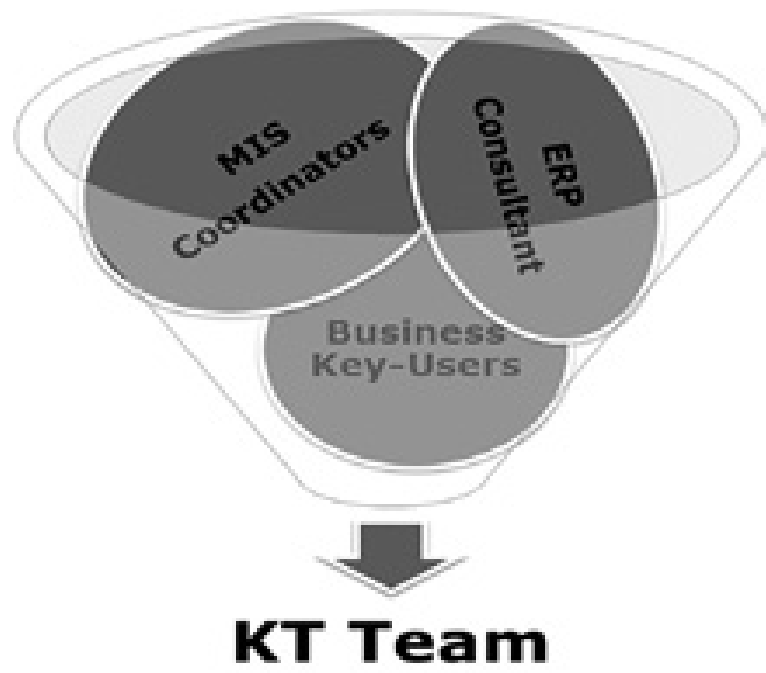

Fig.3: The KT team

\subsection{Knowledge Transfer Methodologies}

The knowledge transfer procedures during ERP implementation can be based on two alternative approaches as shown in figure 4 :

Exploration oriented, involving the users in the implementation process. It is requiring users' active participation in all phases of the project and gradual knowledge transfer from consultants to the users during day-to-day project work.

Instruction oriented, assuming a passive attitude of the users to the implementation and the knowledge transfer process. It is depending on the formal trainings sessions provided by the consultants and not requiring users' active participation in the project activities.

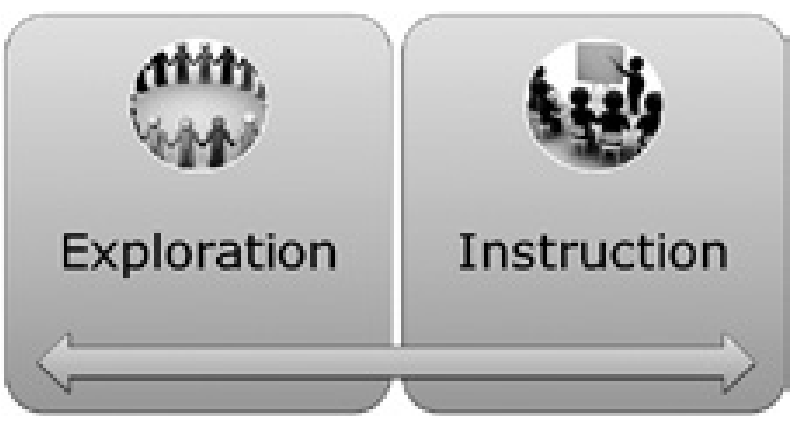

Fig.4: The KT methods
In most ERP implementation projects, the knowledge is transferred using a mix of the two approaches but the ratio varied from project to another. In our proposed framework, we suggested the exploration oriented approach, however, most of the enterprises preferred the instruction based approach.

\subsection{Knowledge Transfer Procedures}

As discussed in the background section and according to ASAP methodology the ERP project consists of five phases as shown in figure 5 , each of them resulting in the delivery of the following main knowledge transfer products:

Project preparation phase: The knowledge product of this phase is the initial training.

Business blueprint: The knowledge product of this phase is the Business Blueprint documentation.

Realization: The knowledge products of this phase are the system documentation and user manuals.

Final preparation: This phase results in the system ready to run and trained users as the main knowledge product.

Go-live and support: The knowledge product of this phase is the lessons learned documentation.

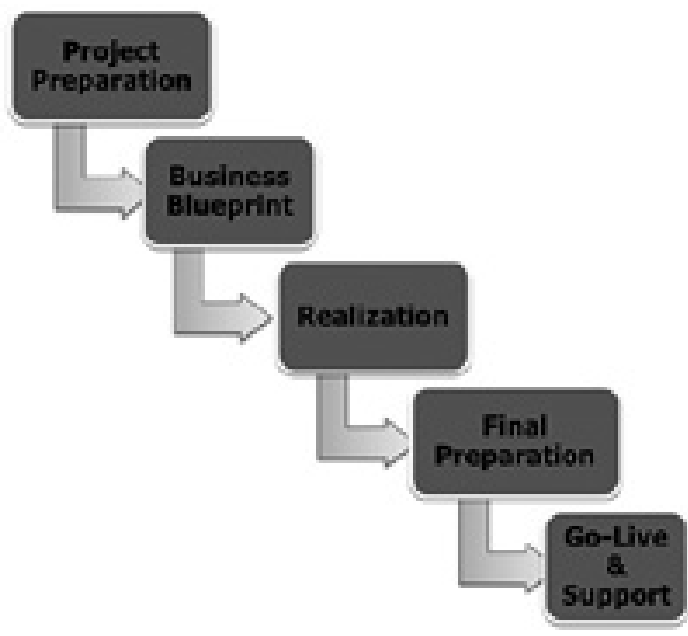

Fig.5: ERP implementation project phases 


\subsection{Proposed Framework Composition}

The previous sections have listed a number of elements that will be very useful when tailoring the knowledge transfer process in the implementation of ERP system. Each of these elements is a key to successfully transfer the knowledge during the ERP implementation and as a result a successful project. Research has been reviewed in three different areas, Enterprise Resource Planning, implementation project, and knowledge Transfer to build a proposed framework for knowledge transfer in ERP implementation projects. By combining lessons learned from each of these areas it will be possible to influence the ability to get the knowledge needed to manage the processes effectively during and after implementation of a new ERP system. The focus of this section is to bring the main areas together and to connect them into a framework that will be used to represent how the knowledge transfer process in any ERP implementation project. The framework was composed of the findings in the theoretical study.

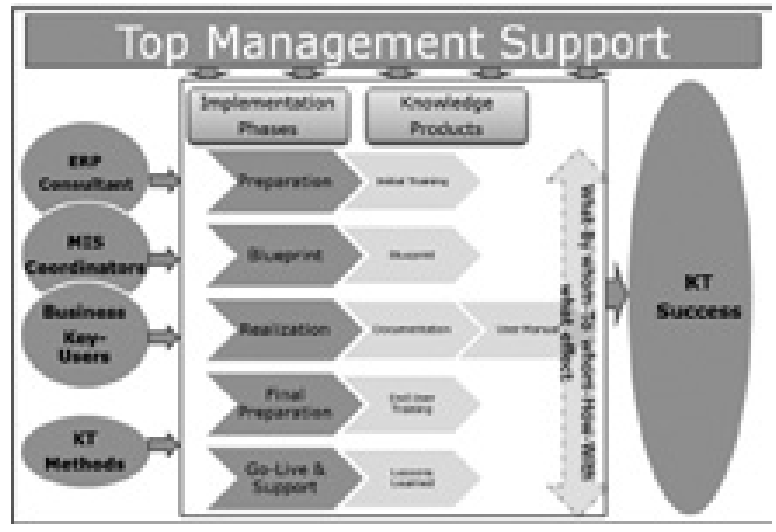

Fig.6: Proposed Framework for KT in ERP implementation project

Figure 6 represents the main three elements used when composing the framework; the first is the knowledge transfer team composed of ERP consultant, MIS coordinators, and Business key-users; the second is knowledge transfer method used, we suggested the ex- ploration oriented approach; the third is the knowledge transfer procedures that composed of the five phases of the ERP implementation project that output the knowledge products of each phase. As shown in the diagram above, during planning to transfer the knowledge we must respond to the following questions: what knowledge to be transferred? - By whom the knowledge will be transferred? - To whom the knowledge will be transferred? - How the knowledge will be transferred? - With what effect the knowledge will be transferred?

The most important success factor for the knowledge is the top management support, without top management involvement, support and commitment the success of knowledge transfer cannot be guaranteed and as result the high risk of ERP implementation project failure.

\section{Summary}

This paper discussed the process of knowledge transfer during ERP implementation. As it is one of the key factors of implementation success, the knowledge transfer procedures should be carefully planned and carried out. A proposed framework for knowledge transfer activities, and roles in ERP implementations. We insisted on using the exploration oriented approach for knowledge transfer, although most of the enterprises preferred the instruction based approach. This research gives enough motivation to any ERP implementation project to focus greatly on the knowledge transfer during the implementation. The proposed framework for knowledge transfer in ERP projects can aid in: reduce costs of ERP implementation and postimplementation support, Increase independence with the installed ERP, and increase the level of satisfaction with ERP implementations.

\section{References:}

[1] "PMI." PMI. Web. 1 May 2015. <http://www.pmi.org/>. 
[2] Alavi, M. and Leidner, D., "Knowledge Management and Knowledge Management Systems: Conceptual Foundation and An Agenda for Research," MIS Quarterly, March 2001, pp. 107-136.

[3] Avraham Shtub. 1999. Enterprise Resource Planning (ERP): The Dynamics of Operations Management. Kluwer Academic Publishers, Norwell, MA, USA.

[4] Carlo, M. Enterprise Software has to fit like a good suit.

[5] Chan, R. and Rosemann, M. (2001) "Managing knowledge in enterprise systems", Journal of Systems and Information Technology, Vol. 5 No. 2, pp.37-54.

[6] Chang, J.Y.T. et al. (2013), "Controlling ERP consultants: Client and provider practices"' Journal of Systems and Software, 86(5), pp.1453-1461.

[7] Davenport, T. 1998. Putting the Enterprise Into The Enterprise System. Havard Business Review, 76(4), 121\{131.

[8] Ehie I, Madsen M. (2005) "Identifying critical issues in enterprise resource planning (ERP) implementation", Computers in Industry, Vol. 56, Issue 6, pp. 545-557.

[9] Erik Bethke (2003). Game Development and Production. p.65.

[10] Griffith T.L., R.F. Zammuto, L. Aiman-Sith, "Why new technologies fail?" Industrial Management, 1999, pp. 29 -34.

[11] King S.F and Burgesss T. F. 2006. 'Beyond critical success factors: A dynamic model of enterprise system innovation'. International Journal of information management, 26: 59-69.

[12] Kumar J.A., Ganesh L.S. (2009) "Research on knowledge transfer in organizations - a morphology", Journal of Knowledge Management, 13(4), pp. 161-174.

[13] Markus, M.L. and Tanis, C. (2000) The enterprise systems experience - from adoption to success. In Framing the Domains of IT Research: Glimpsing the Future through the Past, Zmud, R.W. (ed.) (Pinna $]$ ex Educational Resources, Cincinnati, $\mathrm{OH}), 173-207$.

[14] Markus, M.L., \& Tanis, C. 1999. The Enterprise Expe- rience - From Adoption to Success. Pages 173-208 of: Zmud, R.W. (ed), Framing the domains of IT research: Glimpsing the future from the past. Cincinnati, OH: Pinnaflex Educational Resources, Inc.

[15] Pan, S.L., Newell, S., Huang, J.C. and Wan, K.C. "Knowledge Integration as a Key Problem in an ERP Implementation," in Proceedings of the Twenty Second International Conference on Information Systems, 2001, pp.321 328.

[16] Poston, R., \& Grabski, S. 2001. Financial impacts of enterprise resource planning implmentation. Journal of Accounting Information Systems, 2(4), 271-294.

[17] Robey, D., \& Ross, J.W. 2002. Learinng to Implement Enterprise Systems: An Exploratory Study the Dialects of Change. Journal of Management Information Systems, 19(1), 17-46.

[18] Rosemann,M., "ERP-Software-Characteristics and consequences," Proceedings of the 7th European Conference on Information Systems, J.PriesHeje et al. (eds.) (III), 1999, pp. 1038-1043.

[19] Ross, J. W. 1999 (July/August). Surprising facts about implementing ERP. Tech. rept. IT Pro.

[20] SANKAR, C.S., RAU, K.-H.: Implementation Strategies for SAP R/3 in a Multinational Organization: Lessons from a Real-World Case Study. Cybertech Publishing, 2006, ISBN13978-1591407768.

[21] Umble, E. J., Ronald, R. H., \& Umble, M. M. 2003. Enterprise Resource Planning: Implementation procedures and Critical Success Factors. European Journal of Operational Research, 146: pp. 241-257.

[22] Web. 1 May 2015. <http://patronday.com/tag/-panorama-consulting-solutions-erp-software-selection>.

[23] Zhang, L., Lee, M.K.O., Zhe, Z., \& Banerjee, P. 2003. Critical success factors of enterprise resource planning systems implementation success in China. In: Proceedings of the 36th Annual Hawaii International Conference on System Sciences. 